УДК 616-053.2-058.862:613.95:347.635.2

DOI: $10.26435 /$ UC.V0I4(33).407

Б.И. Кривущев, В.Б. Висягин, С.Я. Ярошенко, Л.А. Захарова, И.А. Ольховик, С.И. Вакуленко

ГОО ВПО «Донецкий национальный медицинский университет имени М. Горького», Донецк

\title{
ЭФФЕКТИВНОСТЬ ИСПОЛЬЗОВАНИЯ КОМПЛЕКСНОЙ ПРОГРАММЫ ОЗДОРОВЛЕНИЯ ДЕТЕЙ-ВОСПИТАННИКОВ ДОМА РЕБЕНКА
}

На территории ДНР проживают 4030 детейсирот и детей, лишенных родительского попечения. Из них на полном государственном обеспечении в учреждениях пребывают 776 детей. Остальные дети воспитываются в семьях граждан. [1]

Приоритетные задачи домов ребенка - воспитание, развитие детей, а также сохранение и преумножение здоровья их воспитанников [2, 3]. Первоочередность этой задачи связана с возрастными особенностями и особенностями альтернативного жизнеустройства сирот. В возрасте до 2-3 лет жизнь и последующее развитие ребенка напрямую зависят от степени внимания, которое ему уделяют взрослые. Обеспечение только базовых витальных потребностей, дефицит внимания к нуждам ребенка со стороны родителей (гипоопека) могут наблюдаться даже во внешне благополучных семьях, а клинические проявления отклонений здоровья ребенка, развивающегося в условиях недостатка материнской опеки, разнообразны: нарушения физического и психомоторного развития без очевидной связи с врожденной или хронической патологией, а также изменения резистентности, при которых острые заболевания регистрируются уже в первом полугодии жизни и могут повторяться с интервалом в 1-2 месяца $[4,5]$.

При поступлении в дома ребенка дети имеют серьезные патологии, угрожающие здоровью. Так, по данным Министерства здравоохранения Российской Федерации, у 64\% обнаруживаются осложнения внутриутробного развития, различная степень асфиксии (у 61,1\%), каждый второй ребенок рождается с признаками перинатальной патологии, 48\% - недоношенными или с низкой массой тела, у 10\% при рождении обнаруживаются врожденные и наследственные заболевания. Острыми респираторными заболеваниями в периоде новорожденности болели 70-80\% воспитанников домов ребенка. Болезни органов дыхания, расстройства питания, снижение иммунитета в 1,5-2 раза чаще регистриру- ются у детей, поступающих в дом ребенка, чем среди их сверстников из семей [6].

Среди этиологических факторов острых респираторных инфекций (ОРИ) у детей ведущую роль играют вирусы, удельный вес которых составляет от 65 до 90\%. В домах ребенка, напротив, больший удельный вес приходится на бактериальные возбудители, что приводит к нарастанию тяжести заболевания и повышению риска развития осложнений (отит, синусит, трахеобронхит, пневмония и др.).

Реабилитационные мероприятия у детей требуют планомерных и систематических медикосоциальных мероприятий, которые включают режим дня, рациональное питание, закаливающие процедуры, иммунокоррекцию [7].

Согласно данным Государственного реестра лекарственных средств Российской Федерации, на 15.02.2015 г. было зарегистрировано более 100 иммуностимуляторов и более 50 иммуномодуляторов, большинство из которых позиционируются как препараты для профилактики и лечения ОРИ. Кроме того, эти показания отмечены у ряда иммунобиологических препаратов [8]. Однако только в отношении некоторых из них в научной литературе представлено достаточное число доказательных данных, которые подтверждают их высокую эффективность и безопасность и, следовательно, дают возможность рекомендовать их для широкого применения в педиатрической практике.

Наибольший интерес представляет систематический обзор, включенный в базу данных Cochrane, посвященный применению иммуномодуляторов для профилактики инфекций респираторного тракта у детей. Авторы обзора проанализировали более 700 публикаций за период с 1966 по 2011 год, из которых было отобрано 61

(c) Б.И. Кривущев, В.Б. Висягин, С.Я. Ярошенко Л.А. Захарова, И.А. Ольховик, С.И. Вакуленко, 2019 (c) Университетская Клиника, 2019 
плацебо-контролируемое клиническое исследование. В этих исследованиях определялись эффективность и безопасность различных иммуномодуляторов: в 40 - бактериальных препаратов (лизаты, рибосомы, антигены), в 11 - синтетических препаратов, в 5 - экстракта тимуса, в 4 - растительных препаратов и в 1 - интерферона. В итоговый мета-анализ, показавший снижение частоты инфекций респираторного тракта на 35,9\% (95\% ДИ= 49,5 - 22,4) [9], вошли 35 исследований, в которых участвовало более 4 тысяч детей,.

Эффективность иммунореабилитационных мероприятий в условиях закрытых коллективов домов ребенка при этом изучена мало [10-12].

В связи с этим целью работы явилось изучение эффективности комплексной программы оздоровления детей-воспитанников дома ребенка.

\section{МАТЕРИАЛ И МЕТОДЫ}

Под наблюдением находилось 75 детей, воспитывающихся в доме ребенка, в возрасте от полутора до трех лет включительно. Основную группу и группу сравнения формировали методом жеребьевки. Основную группу составили 23 ребенка, получавшие комплекс оздоровительных мероприятий: фито-чай (лист смородины и цветки липы) по 50,0 мл 3 раза в день за 30 мин до еды в течение 1-го месяца с целью укрепления организма и повышения иммунитета; сироп корня солодки (по 2,0 мл 1 раз в день) в течение месяца (выводит из организма токсины, стимулирует работу надпочечников, снимает спазмы и воспаления, нормализует кровоток, водный баланс и обмен веществ в организме); витамины «Алфавит. Наш малыш» (№ 1 - завтрак, № 2 - обед, № 3 - ужин, во время еды) в течение 1-го месяца как дополнительный источник витаминов и минеральных веществ (макро- и микроэлементов); водорастворимый витамин D - «Аквадетрим» (по 2 капли 1 раз в день) в течение трех месяцев. Дополнительное назначение витамина D обусловлено данными о его участии в иммунитете (иммунные клетки экспрессируют СУР27В1). В комплекс оздоровительных мероприятий также включены: ультрафиолетовое облучение (УФО) - общее и зоны надпочечников № 10 (оказывает положительное влияние на иммунную систему и способствует активизации факторов неспецифической резистентности организма [13]); массаж воротниковой зоны № 10; лечебная физкультура (ЛФК) по 20-30 минут № 15 с целью увеличения притока к мозгу крови, питательных веществ и кислорода; прогулки на свежем воздухе 2 раза в день не менее 30 минут ежедневно; классическая релаксирующая музы- ка при засыпании ежедневно. Основная группа получала также бактериальные лизаты (OM-85) трехкратным курсом по традиционной схеме: 1 капсула утром до еды продолжительностью 10 дней с перерывами между курсами в 20 дней.

Группу сравнения составили 22 ребенка, получавшие только комплекс оздоровления и не получавшие курс бактериальных лизатов.

Ретроспективно методом «копи-пара» сформировали группу контроля (30 детей), сопоставимую по полу, возрасту, сопутствующим заболеваниям, условиям жизни и времени года (с учетом сезонности).

Оценивались следующие показатели: частота ОРИ в течение года; средняя продолжительность одного случая ОРИ; количество антибактериальных препаратов, полученных одним ребенком за время наблюдения; количество антибактериальных препаратов на один случай заболевания ОРИ.

Проверка данных на соответствие нормальному закону распределения (Шапиро-Уилка) показала, что во всех случаях распределение отличалось от нормального. Поэтому для статистического анализа использованы непараметрические методы: при сравнении независимых выборок - Kruskal-Wallis Rank Test, при связанных - Wilcoxon Signg Rank Test. Статистическая обработка проводилась при помощи пакета Statistika 6.0. Формат представления данных: в тексте и таблице - среднее арифметическое \pm стандартные отклонения (медиана; минимум - максимум).

\section{РЕЗУЛЬТАТЫ И ОБСУЖДЕНИЕ}

Среди детей, получавших комплекс оздоровления с использованием бактериального лизата (основная группа), частота острых респираторных инфекций в пересчете на 365 дней до начала программы составила $6,4 \pm 1,9$ случая $(\mathrm{Me}=6,3$;

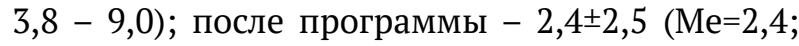
$0,0-7,2)$. В группе сравнения частота ОРИ была $7,6 \pm 2,2(\mathrm{Me}=8,2 ; 6,1-8,8)$ и 4,4 $42,7(\mathrm{Me}=4,8 ; 0,0-$ $8,7)$ до и после проведения комплекса оздоровления соответственно. В группе контроля пока-

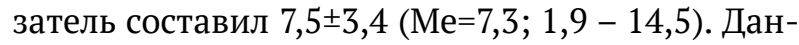
ные представлены в таблице.

Иммуномодулятор бактериального происхождения ОМ-85 представляет собой стандартизованный лизат 8 бактерий (4 грамположительных и 4 грамотрицательных), являющихся наиболее частыми возбудителями инфекции дыхательных путей и ЛОР-органов: Streptococcus pneumoniae, Streptococcus viridans, Streptococcus pyogenes, Staphylococcus aureus, Haemophilus influenzae, Moraxella catarrhalis, Klebsiella pneumoniae, Klebsiella ozaenae. Исследования 
Сравнительная оценка эффективности комплексной программы оздоровления

Таблица.

\begin{tabular}{|c|c|c|c|c|c|c|c|}
\hline & \multicolumn{3}{|c|}{ Основная группа, n=23 } & \multicolumn{3}{|c|}{ Группа сравнения, n=22 } & \multirow{3}{*}{$\begin{array}{c}\text { Кон- } \\
\text { трольная } \\
\text { груп- } \\
\text { па, } \mathrm{n}=30\end{array}$} \\
\hline & $\begin{array}{l}\text { До про- } \\
\text { граммы }\end{array}$ & $\begin{array}{l}\text { Во вре- } \\
\text { мя про- } \\
\text { граммы } \\
\end{array}$ & $\begin{array}{c}\text { По- } \\
\text { сле про- } \\
\text { граммы } \\
\end{array}$ & $\begin{array}{l}\text { До про- } \\
\text { граммы }\end{array}$ & $\begin{array}{l}\text { Во вре- } \\
\text { мя про- } \\
\text { граммы }\end{array}$ & $\begin{array}{c}\text { По- } \\
\text { сле про- } \\
\text { граммы } \\
\end{array}$ & \\
\hline & 1 & 2 & 3 & 4 & 5 & 6 & \\
\hline Частота ОРИ за год & $\begin{array}{l}6,4 \pm 1,9^{3)} \\
\mathrm{Me}=6,3 \\
3,8-9,0\end{array}$ & $\begin{array}{c}8,4 \pm 4,0^{3)} \\
\mathrm{Me}=8,0 \\
4,0-16,0\end{array}$ & $\begin{array}{c}2,4 \pm 2,5 * \\
\mathrm{Me}=2,4 \\
0,0-7,2\end{array}$ & $\begin{array}{c}7,6 \pm 2,2 \\
\mathrm{Me}=8,2 \\
6,1-8,8\end{array}$ & $\begin{array}{c}6,8 \pm 3,3 \\
\mathrm{Me}=6,0 \\
4,0-12,0\end{array}$ & $\begin{array}{c}4,2 \pm 2,7 * \\
\mathrm{Me}=4,8 \\
0,0-8,7\end{array}$ & $\begin{array}{c}7,5 \pm 3,4 \\
\mathrm{Me}=7,3 \\
1,9-14,5\end{array}$ \\
\hline $\begin{array}{l}\text { Средняя продолжи- } \\
\text { тельность случая за- } \\
\text { болевания ОРИ }\end{array}$ & $\begin{array}{c}10,9 \pm 1,9)^{3)} \\
\mathrm{Me}=10,3 \\
8,6-13,6\end{array}$ & $\begin{array}{c}9,1 \pm 2,6^{3)} \\
\mathrm{Me}=8,5 \\
6,5-14,5\end{array}$ & $\begin{array}{c}7,8 \pm 2,4 \\
\mathrm{Me}=7,0 \\
5,0-12,0\end{array}$ & $\begin{array}{c}9,8 \pm 2,6 \\
\mathrm{Me}=9,6 \\
6,0-14,0\end{array}$ & $\begin{array}{c}9,3 \pm 3,8 \\
\mathrm{Me}=8,5 \\
5,0-16,0\end{array}$ & $\begin{array}{l}10,3 \pm 3,5 \\
\mathrm{Me}=10,3 \\
6,5-17,0\end{array}$ & $\begin{array}{c}8,9 \pm 2,3 \\
\mathrm{Me}=9,5 \\
4,0-12,6\end{array}$ \\
\hline $\begin{array}{l}\text { Количество антибак- } \\
\text { териальных препара- } \\
\text { тов, полученных од- } \\
\text { ним ребенком за вре- } \\
\text { мя наблюдения }\end{array}$ & $\begin{array}{c}9,2 \pm 4,1^{3), 4)} \\
\mathrm{Me}=9,0 \\
3,0-15,0\end{array}$ & $\begin{array}{c}1,6 \pm 0,7^{3)} \\
\mathrm{Me}=1,0 \\
1,0-3,0\end{array}$ & $\begin{array}{c}0,3 \pm 0,5^{*} \\
\mathrm{Me}=0 \\
0,0-1,0\end{array}$ & $\begin{array}{c}4,3 \pm 4,3^{6)} \\
\mathrm{Me}=3,0 \\
0,0-13,0\end{array}$ & $\begin{array}{c}0,9 \pm 1,0 * \\
\mathrm{Me}=1,0 \\
0,0-3,0\end{array}$ & $\begin{array}{l}0,8 \pm 1,4^{*} \\
\mathrm{Me}=0 \\
0,0-4,0\end{array}$ & $\begin{array}{c}8,6 \pm 4,7 \\
\mathrm{Me}=8,0 \\
2,0-18,0\end{array}$ \\
\hline $\begin{array}{l}\text { Количество антибак- } \\
\text { териальных препа- } \\
\text { ратов на } 1 \text { случай за- } \\
\text { болевания ОРИ }\end{array}$ & $\begin{array}{c}1,0 \pm 0,4^{3), 4)} \\
\mathrm{Me}=0,8 \\
0,5-1,8\end{array}$ & $\begin{array}{c}0,8 \pm 0,6^{3)^{*}} \\
\mathrm{Me}=0,5 \\
0,0-2,0\end{array}$ & $\begin{array}{c}0,2 \pm 0,3^{*} \\
\mathrm{Me}=0,0 \\
0,0-1,0\end{array}$ & $\begin{array}{c}0,6 \pm 0,4^{6)} \\
\mathrm{Me}=0,7 \\
0,0-1,0\end{array}$ & $\begin{array}{l}0,5 \pm 0,5 \\
\mathrm{Me}=0,5 \\
0,0-1,0\end{array}$ & $\begin{array}{c}0,2 \pm 0,4^{*} \\
\mathrm{Me}=0 \\
0,0-1,0\end{array}$ & $\begin{array}{c}0,8 \pm 0,3 \\
\mathrm{Me}=0,8 \\
0,3-1,5\end{array}$ \\
\hline
\end{tabular}

Примечания:

* - статистическое различие с контрольной группой значимо на уровне 0,05 и менее;

2), 3),4),6) - статистически значимое различие с соответствующим номером столбца.

показывают, что бактериальные лизаты способны оказывать существенное регуляторное влияние на функцию иммунной системы. Бактериальные лизаты, в отличие от типичных вакцин, вводимых парентерально, вводят перорально 3,5 мг лиофилизированного экстракта детям и 7 мг взрослым. В кишечнике бактериальные антигены лизатов достигают пейеровых бляшек, воздействуют на дендритные клетки, примируя их и активируя тем самым Т- и В-лимфоциты, а затем распространяются по организму и достигают слизистой оболочки дыхательных путей, повышая иммунный надзор на слизистых.

Согласно современным представлениям, иммунитет ребенка «созревает» под воздействием антигенной стимуляции. В то же время можно говорить о ее дисбалансе в современных условиях: с одной стороны, бактериальные антигены воздействуют на пациента значительно реже, чем 30-40 лет назад, что обусловлено возросшим уровнем гигиены, снижением количества контактов, относительной редкостью бактериальных инфекций, в том числе - из-за применения антибиотиков. С другой стороны, возросла роль латентных, чаще всего - вирусных инфекций. Это приводит, в свою очередь, к иммунному дисбалансу: уменьшается активность
Т-хелперов первого типа и продукция цитокинов, обеспечивающих адекватный иммунный ответ против инфекций: $\gamma$-интерферонов, интерлейкинов 1 и 2 и др. в сторону преобладания цитокинового спектра, характерного для хелперов 2-го типа.

Подавление продукции указанных цитокинов может быть связано также с очень частым использованием при острых инфекционных заболеваниях различных медикаментов, в том числе жаропонижающих средств. В то же время происходит увеличение силы иммунного ответа Th-2, для которого, в частности, характерно повышение продукции IgE и развитие аллергической патологии. Применение бактериальных лизатов приводит к «переключению» иммунного ответа с Th-2 на Th-1, что, соответственно, проявляется повышением уровня противоинфекционной защиты и снижением продукции IgE и аллергизации организма. Применение бактериальных лизатов приводит к увеличению продукции антител класса IgA (в т. ч. секреторных), естественных киллеров [14].

Выраженное воздействие программа оздоровления оказала на среднюю продолжительность одного случая острой респираторной инфекции: в основной группе она составила: до 


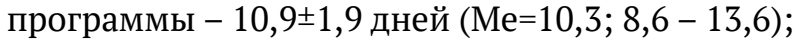

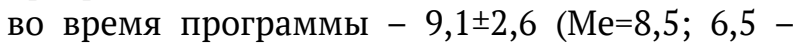
$14,5)$; после программы - 7,8 2 ,4 $(\mathrm{Me}=7,0 ; 5,0$ $12,0)$. В группе сравнения изменения этого показателя были незначительными: до программы - 9,8 2 ,6 дней $(\mathrm{Me}=9,6 ; 6,0-14,0)$; во время - 9,3 $\pm 3,8(\mathrm{Me}=8,5 ; 5,0-16,0)$ и после - 10,3 $\pm 3,5$ $(\mathrm{Me}=10,3 ; 6,5$ - 17,0). Показатель контрольной группы составил $8,9 \pm 2,3$ дней $(\mathrm{Me}=9,5 ; 4,0$ 12,6).

Следовательно, средняя продолжительность случая острой респираторной инфекции в основной группе после программы оздоровления уменьшилась почти на $40 \%$, что может быть объяснено большим количеством иммунокомпетентных клеток и антител, а значит - более ранним началом специфического иммунного ответа при возникновении осложнений у пациентов, получавших бактериальные лизаты, и восстановлением биоценоза слизистых под воздействием бактериальных лизатов в сторону уменьшения «госпитальности» флоры [15].

Учитывая, что при лечении острых респираторных инфекций в домах ребенка традиционно (в связи с особенностями спектра возбудителей в закрытом коллективе) применяется большое количество антибактериальных препаратов (аминопенициллины, цефалоспорины, макролиды), мы провели анализ количества антибактериальных препаратов, полученных одним ребенком (в пересчете на 365 дней): в основной группе до программы оно составило 9,2 $\pm 4,1(\mathrm{Me}=9,0 ; 3,0-15,0)$, во время - 1,6 $\pm 0,7$ $(\mathrm{Me}=1,0 ; 1,0-3,0)$, после - 0,3 $\pm 0,5(\mathrm{Me}=0,0 ; 0,0$ $1,0)$; в группе детей, не получавшей бактериаль-

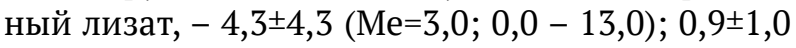
$(\mathrm{Me}=1,0 ; 0,0-3,0)$ и $0,8 \pm 1,4(\mathrm{Me}=0,0 ; 0,0-4,0)$ соответственно. Так, дети, получавшие комплекс оздоровления (группы основная и сравнения, объединенные данные), имели следующие показатели по количеству антибактериальных препаратов, полученных одним ребенком за время наблюдения: до программы оздоровления 6,8 $\pm 4,6(\mathrm{Me}=6,0 ; 1,0-15,0)$; во время программы - 1,2 $\pm 0,9$ (Me=1,0; 0,0 - 3,0); после программы 0,6士1,1 (Me=0,0; 0,0 - 4,0). В контрольной груп-

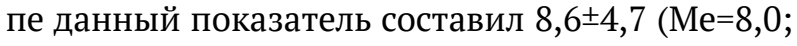
$2,0-18,0)$.

Проведение комплекса оздоровления привело к снижению частоты и длительности острых респираторных заболеваний, а также потребности в антибактериальной терапии (АБТ) - коли- чество антибактериальных препаратов на один случай заболевания значительно снизилось: если до начала программы практически каждый случай ОРИ у детей основной группы сопровождался назначением антибактериальных препаратов $(1,0 \pm 0,4, \mathrm{Me}=0,8 ; 0,5-1,8)$, то во время курса оздоровления - 0,8 $\pm 0,6(\mathrm{Me}=0,5 ; 0,0-$ $2,0)$, а после программы назначение антибиотиков требовалось только в каждом пятом случае $-0,2 \pm 0,3(\mathrm{Me}=0,0 ; 0,0-1,0)$. В группе сравнения динамика схожая: $0,6 \pm 0,4(\mathrm{Me}=0,7 ; 0,0-1,0)$; $0,5 \pm 0,5(\mathrm{Me}=0,5 ; 0,0-1,0)$ и $0,2 \pm 0,4(\mathrm{Me}=0,0 ; 0,0-$ $1,0)$ соответственно, т.е. потребность в антибактериальных препаратах снизилась практически в 3-5 раз.

При подсчете частоты применения антибактериальной терапии у объединенной группы детей, получавших комплекс оздоровления (n=45), выявлено, что до программы оздоровления в 4 из 5 случаев ОРИ назначались антибактериальные препараты $(0,8 \pm 0,3, \mathrm{Me}=0,5 ; 0,0-2,0)$; во время программы - 0,6 $\pm 0,6(\mathrm{Me}=0,5 ; 0,0-2,0)$; после программы - 0,2 $\pm 0,4(\mathrm{Me}=0,0 ; 0,0-1,0)$ при показателях контрольной группы - 0,8 $\pm 0,3$ $(\mathrm{Me}=0,8 ; 0,3-1,5)$. Таким образом, потребность в АБТ снизилась в 4 раза, что подтверждает положительный клинический эффект предлагаемого комплекса оздоровления, а также позволяет говорить о значительной фармако-экономической выгоде применения данного комплекса.

\section{В Ы В О д Ы}

1. Дети в доме ребенка болеют чаще в 1,5-2 раза, чем их сверстники из семей.

2. Применение комплекса оздоровительных мероприятий показало снижение частоты острых респираторных инфекций, количества антибактериальных препаратов, использования антибактериальных препаратов на один случай заболевания ОРИ.

3. Применение в комплексе оздоровления бактериальных лизатов позволило снизить частоту ОРИ за год в 2,7 раза по сравнению с детьми контрольной группы, в 1,4 раза уменьшить среднюю продолжительность одного случая ОРИ, а также снизить частоту применения антибактериальных препаратов в 5 раз.

4. Снижение потребности в антибактериальных препаратах позволяет избежать побочных эффектов терапии и уменьшить финансовые затраты на лечение ОРИ в условиях закрытого коллектива дома ребенка. 
Б.И. Кривущев, В.Б. Висягин, С.Я. Ярошенко, Л.А. Захарова, И.А. Ольховик, С.И. Вакуленко

ГОО ВПО «Донецкий национальный медицинский университет имени М. Горького», Донецк

\section{ЭФФЕКТИВНОСТЬ ИСПОЛЬЗОВАНИЯ КОМПЛЕКСНОЙ ПРОГРАММЫ ОЗДОРОВЛЕНИЯ ДЕТЕЙ-ВОСПИТАННИКОВ ДОМА РЕБЕНКА}

Изучена эффективность комплексной программы оздоровления у 75 детей, воспитывающихся в доме ребенка, в возрасте от 1,5 до 3 лет включительно. Основную группу составили 23 ребенка, получавшие комплекс оздоровительных мероприятий, в который входили: фито-чаи (лист смородины и цветки липы); сироп корня солодки; поливитаминный комплекс, а также дополнительно - водорастворимый витамин D; ультрафиолетовое облучение - общее и зоны надпочечников; массаж воротниковой зоны; лечебная физкультура; прогулки на свежем воздухе; классическая релаксирующая музыка при засыпании ежедневно. Кроме данного комплекса, основная группа получала также бактериальный лизат ОМ-85 по стандартной схеме. Группу сравнения составили 22 ребенка, получавшие только основной комплекс оздоровления, без бактериальных лизатов. Распределение по группам проводилось методом жеребьевки. Ретроспективно методом «копи-пара» сформировали группу контроля (30 детей), сопоставимую по полу, возрасту, сопут- ствующим заболеваниям, условиям жизни и времени года (с учетом сезонности).

Установлено, что применение комплекса оздоровительных мероприятий показало снижение частоты острых респираторных инфекций, количества антибактериальных препаратов, использования антибактериальных препаратов на один случай заболевания острой респираторной инфекцией.

Применение в комплексе оздоровления бактериальных лизатов позволило снизить частоту острых респираторных инфекций за год в 2,7 раза по сравнению с детьми контрольной группы, в 1,4 раза уменьшить среднюю продолжительность одного случая острой респираторной инфекции, а также снизить частоту применения антибактериальных препаратов в 5 раз.

Ключевые слова: дети, программа оздоровления, бактериальные лизаты, острые респираторные инфекции.

\section{B.I. Krivushchev, V.B. Visyagin, S.Ya. Yaroshenko, L.A. Zakharova, I.A. Olkhovik, S.I. Vakulenko}

SEI HPE «M. Gorky Donetsk National Medical University», Donetsk

\section{EFFICIENCY OF USING A COMPREHENSIVE HEALTH IMPROVEMENT PROGRAMME FOR CHILDREN FROM ORPHANAGES}

The efficiency of a comprehensive health improvement programme was studied in 75 children living in an orphanage, aged 1.5 to 3 years, inclusive. The main group consisted of 23 children who received a range of recreational activities: herbal teas (currant leaf and linden flowers); licorice root syrup; multivitamin complex, and additionally water soluble vitamin $\mathrm{D}$; ultraviolet radiation: general and to the adrenal glands; collar zone massage; physiotherapy; walks in the open air; classic relaxing music during falling asleep. In addition to this complex, the main group also received the bacterial lysate OM-85 according to the standard scheme. The comparison group consisted of 22 children who received only the main health improvement complex, without bacterial lysates. The distribution of the groups made by the draw method. In retrospect, the "copy-pair" method formed a control group (30 children), comparable by sex, age, con- comitant diseases, living conditions and time of year (seasonally adjusted).

It was found that the use of a set of health improvement measures showed a decrease: the frequency of acute respiratory infections, the number of antibacterial drugs, the use of antibacterial drugs for one case of acute respiratory infection.

The use of bacterial lysates in the health improvement complex made it possible to reduce the frequency of acute respiratory infections per year by 2.7 times compared with children in the control group, to reduce 1.4 times the average duration of one case of acute respiratory infection, and also to reduce the frequency of antibacterial drugs by 5 times.

Key words: children, health improvement programme, bacterial lysates, acute respiratory infections.

\section{ЛИТЕРАТУРА}

1. За 9 месяцев 2019 в ДНР усыновлены 32 ребенка. DNR LIVE Деловой портал. URL: https://dnr-live.ru/za-9-mesyatsev-2019-v-dnr-usyinovlenyi-32-rebenka/ (дата обращения: 09.10.2019).

2. Райский Д.В., Джумагазиев А.А., Джальмухамедова Э.И., Вайнер А.Е. Особенности затяжной адаптации детей в доме ребенка. Российский педиатрический журнал. 2014; 5: 9-15.

3. Лазуренко С.Б. Организация коррекционно-педагоги-

\section{REFERENCES}

1. Za 9 mesyatsev 2019 v DNR usynovleny 32 rebenka. DNR LIVE Delovoi portal. URL: https://dnr-live.ru/za-9-mesyatsev-2019-v-dnr-usyinovlenyi-32-rebenka/ (data obrashcheniya: 09.10.2019) (in Russian).

2. Raiskii D.V., Dzhumagaziev A.A., Dzhal'mukhamedova E.I., Vainer A.E. Osobennosti zatyazhnoi adaptatsii detei v dome rebenka. Rossiiskii pediatricheskii zhurnal. 2014; 5: 9-15 (in Russian). 
ческой помощи в домах ребенка при сочетанной перинатальной патологии у детей раннего возраста. Российский педиатрический журнал. 2011; 4: 59-61.

4. Джумагазиев А.А., Райский Д.В., Джальмухамедова Э.И., Савина Н.А., Иноземцева О.А. Персистирующее течение респираторных заболеваний у детей домов ребенка: возможные причины. В кн.: Материалы V Российского форума «Здоровье детей: профилактика социально-значимых заболеваний. Санкт-Петербург 2011». 12-13 мая 2011 г. СПб.; 2011: 68-70.

5. Райский Д.В., Джумагазиев А.А., Паньковская О.И., Савенкова Н.Д. Эпидемиологические особенности острых бронхитов у астраханских детей от 0 до 5 лет жизни с 2002 по 2012 годы. В кн.: Современная наука и образование: инновационный аспект: Сборник научных трудов по материалам международной научнопрактической конференции 31 июля 2013 г. Часть I. М.: «АР-Консалт»; 2013: 22.

6. Юлиш Е.И., Балычевцева И.В., Висягин В.Б., Кривущев Б.И., Ярошенко С.Я., Лютова Т.А. Состояние здоровья детей домов ребенка. Здоровье ребенка. 2010; 5 (26): 56-62.

7. Ярилин А.А. Основы иммунологии. М.; 2002. 30.

8. Государственный реестр лекарственных средств. URL: grls.rosminzdrav.ru (дата обращения: 15.02.2015)

9. Del Rio Navarro B.E., Espinosa-Rosales F.J., Flenady V., Sienra-Monge J.J.L. Immunostimulants for preventing respiratory tract infection in children (Review). Evid.-Based Child Health. 2012; 7 (2): 629-717.

10. Юлиш Е.И, Ярошенко С.Я. Часто болеющие дети и тактика педиатра. Здоровье ребенка. 2013; 6 (49): 70-76.

11. Самсыгина Г.А., Выжлова Е.Н. Еще раз о проблемах понятия «Часто болеющие дети». Педиатрия. 2016; 4: 209-215.

12. Бабаян М.Л. Часто болеющие дети: проблемы терапии острых респираторных инфекций у детей. Медицинский совет. 2014; 14: 11-13.

13. Чичкан Д.Н., Улащик В.С., Волотовская А.В. Ультрафиолетовое излучение и искусственный загар. Мински: Бизнесофсет; 2005. 246.

14. Huber M., Mossmann H., Bessler W. G. Th1-orientated immunological properties of the bacterial extract OM-85 -BV. Eur. J. Med. Res. 2005; 10, 5: 209-217.

15. Таточенко В. К., Озерецковский Н. А., Федоров А.М. Иммунопрофилактика - 2014. М.: ПедиатрЂ; 2014. 199.
3. Lazurenko S.B. Organizatsiya korrektsionno-pedagogicheskoi pomoshchi $\mathrm{v}$ domakh rebenka pri sochetannoi perinatal'noi patologii u detei rannego vozrasta. Rossiiskii pediatricheskii zhurnal. 2011; 4: 59-61 (in Russian).

4. Dzhumagaziev A.A., Raiskii D.V., Dzhal'mukhamedova E.I., Savina N.A., Inozemtseva O.A. Persistiruyushchee techenie respiratornykh zabolevanii u detei domov rebenka: vozmozhnye prichiny. V kn.: Materialy V Rossiiskogo foruma «Zdorov'e detei: profilaktika sotsial'no-znachimykh zabolevanii. Sankt-Peterburg - 2011». 12-13 maya 2011 g. SPb.; 2011: 68-70 (in Russian).

5. Raiskii D.V., Dzhumagaziev A.A., Pan'kovskaya O.I., Savenkova N.D. Epidemiologicheskie osobennosti ostrykh bronkhitov $\mathrm{u}$ astrakhanskikh detei ot 0 do 5 let zhizni $\mathrm{s}$ 2002 po 2012 gody. V kn.: Sovremennaya nauka i obrazovanie: innovatsionnyi aspekt: Sbornik nauchnykh trudov po materialam mezhdunarodnoi nauchno-prakticheskoi konferentsii 31 iyulya 2013 g. Chast' I. M.: «AR-Konsalt»; 2013: 22 (in Russian).

6. Yulish E.I., Balychevtseva I.V., Visyagin V.B., Krivushchev B.I., Yaroshenko S.Ya., Lyutova T.A. Sostoyanie zdorov'ya detei domov rebenka. Zdorov'e rebenka. 2010; 5 (26): 5662 (in Russian).

7. Yarilin A.A. Osnovy immunologii. M.; 2002. 30 (in Russian).

8. Gosudarstvennyi reestr lekarstvennykh sredstv. URL: grls. rosminzdrav.ru (data obrashcheniya: 15.02.2015) (in Russian).

9. Del Rio Navarro B.E., Espinosa-Rosales F.J., Flenady V., Sienra-Monge J.J.L. Immunostimulants for preventing respiratory tract infection in children (Review). Evid.-Based Child Health. 2012; 7 (2): 629-717.

10. Yulish E.I, Yaroshenko S.Ya. Chasto boleyushchie deti i taktika pediatra. Zdorov'e rebenka. 2013; 6 (49): 70-76 (in Russian).

11. Samsygina G.A., Vyzhlova E.N. Eshche raz o problemakh ponyatiya «Chasto boleyushchie deti». Pediatriya. 2016; 4: 209-215 (in Russian).

12. Babayan M.L. Chasto boleyushchie deti: problemy terapii ostrykh respiratornykh infektsii $u$ detei. Meditsinskii sovet. 2014; 14: 11-13 (in Russian).

13. Chichkan D.N., Ulashchik V.S., Volotovskaya A.V. Ul'trafioletovoe izluchenie i iskusstvennyi zagar. Minski: Biznesofset; 2005. 246 (in Russian).

14. Huber M., Mossmann H., Bessler W. G. Th1-orientated immunological properties of the bacterial extract OM-85 -BV. Eur. J. Med. Res. 2005; 10, 5: 209-217.

15. Tatochenko V. K., Ozeretskovskii N. A., Fedorov A.M. Immunoprofilaktika - 2014. M.: Pediatr; 2014. 199 (in Russian). 